\title{
verals
}

ISSN 2236-5729

\section{Queremos o nosso playground! Participação e cidadania na infância: entraves e possibilidades}

\section{We want our playground! Participation and citizenship in childhood: barriers and possibilities}

Tássio José da Silva é mestre em Educação pela Universidade Federal de São Paulo, Coordenador Pedagógico na Prefeitura de São Paulo e Professor do curso de Pedagogia do Centro Universitário Anhanguera de São Paulo.

Contato: tassiojosedasilva@gmail.com

\section{Resumo}

Este artigo tem como objetivo problematizar a cidadania na infância e a possibilidade de participação das crianças na estrutura político-social das sociedades. A partir de uma reflexão teórica inicialmente inspirada pelas configurações do protesto das crianças do Quênia, aliada à análise de documentos recentemente publicados por organismos internacionais, apresentaremos os entraves e possibilidades que se colocam na efetivação da participação das crianças como sujeitos de direitos. 0 processo de construção e fortalecimento de uma Pedagogia da Educação Infantil, somado à consolidação de mecanismos teóricos e práticos que efetivem o protagonismo político e social das crianças, apresenta-se como questão fundante na atualidade, focada nesta reflexão.

Palavras-chave: Cidadania, infância, participação.

\section{Abstract}

This article aims to discuss citizenship in childhood and the possibility of participation of children in political and social structures of societies. From a theoretical reflection initially inspired by the protest settings of children in Kenya, together with the analysis of documents recently published by international organizations, it presents the obstacles and opportunities that arise in the execution of the participation 
of children as subjects of rights. The process of building and strengthening an Early Childhood Education Pedagogy, coupled with the consolidation of theoretical and practical mechanisms to give effect to the political and social role of children, appears as insurgent question today, and it's focused in this reflection.

Keywords: Citizenship. Childhood. Participation

\section{Introdução ou o protesto das crianças do Quênia: o que aprendemos com elas?}
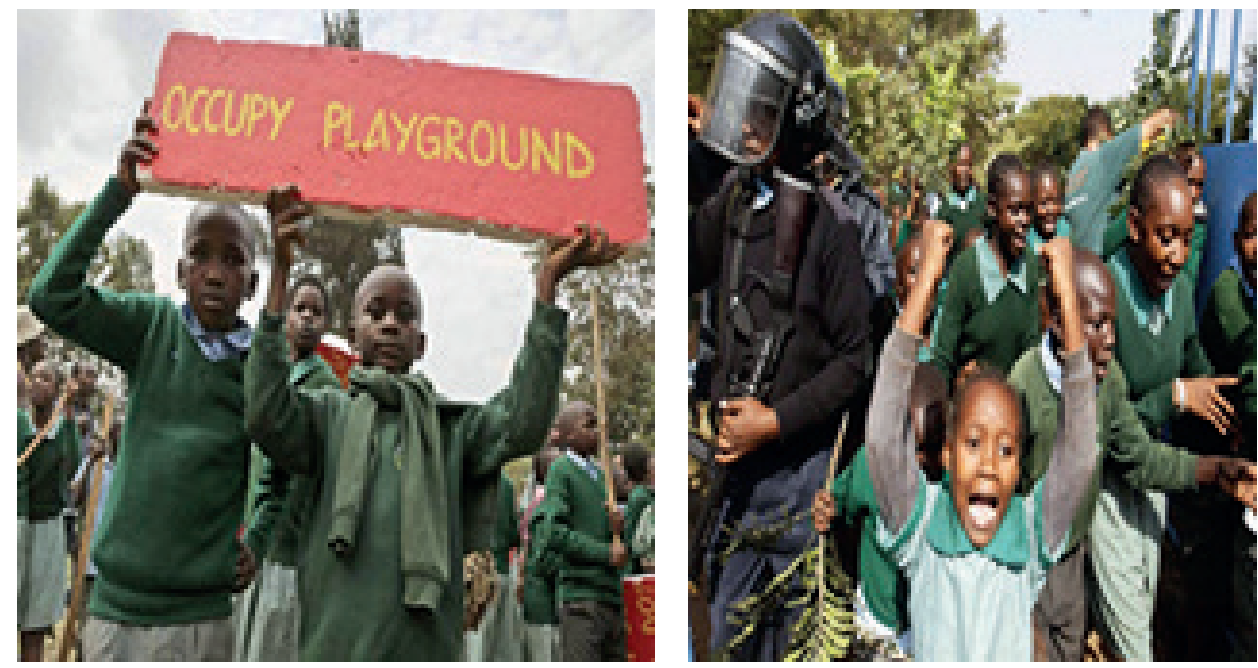

A polícia do Quênia lançou gás lacrimogêneo contra crianças que protestavam nesta segunda-feira (19) em Nairóbi contra a retirada do playground da escola em que estudam. Segundo um ativista local, o parquinho teria sido retirado a mando de um poderoso político do país para se tornar um estacionamento. Os alunos da escola primária Langata Road estiveram à frente do grupo de pessoas que derrubaram o muro erguido que cercava o playground. Os alunos da escola têm entre seis e 14 anos de idade, segundo o ativista Boniface Mwangi. "O governador, o senador e outras autoridades governamentais estão com medo do político, eles não podem fazer nada para impedir que o playground seja tomado", disse Mwangi'.

O presente artigo tem por objetivo problematizar a cidadania na infância e a possibilidade de participação das crianças na estrutura político-social das sociedades. De maneira introdutória, trazemos para o debate a reportagem jornalística amplamente divulgada que retrata o protesto realizado pelas crianças no Quênia em janeiro de 2015, no continente africano, contra a retirada do playground da escola onde estudam. Tal fato possui uma representatividade simbólica importante e necessária, que nos instiga a refletir, justamente, sobre o objetivo deste artigo e construir alguns questionamentos que procuraremos responder ao longo desta reflexão.

1. Disponível em: http://g1.globo. com/mundo/noticia/2015/01/ policia-do-quenia-lanca-gas-lacrimogenio-em-protestode-criancas.html 
As crianças participam efetivamente das decisões que afetam suas vidas? Como os conceitos de infância e de socialização nos ajudam a compreender o papel social ocupado pelas crianças? Quais as possibilidades e potencialidades para a promoção da cidadania na infância? Em caráter complementar, apresento alguns dados recentemente lançados por organismos internacionais, entre eles, o Fundo das Nações Unidas para a Infância (UNICEF) e a Organização das Nações Unidas para a Educação, a Ciência e a Cultura (UNESCO), sobre os modos de vida das crianças, com o objetivo de aprofundar e compor nossas análises sobre a participação infantil e sobre a cidadania na infância.

\title{
A infância como categoria de análise
}

\begin{abstract}
As crianças, todas as crianças, transportam o peso da sociedade que os adultos Ihes legam, mas fazem-no com a leveza da renovação e o sentido de tudo que é novo é possível. É por isso que o lugar da infância é um entre-lugar (Bhabha, 1998), o espaço intersticial entre dois modos - o que é consignado pelos adultos e o que é reinventado nos mundos de vida das crianças - e entre dois tempos - o passado e o futuro. É um lugar, um entre-lugar, socialmente construído, mas existencialmente renovado pela acção colectiva das crianças. Mas um lugar, um entre-lugar, pré-disposto nas suas possibilidades e constrangimentos pela história (SARMENTO, 2004, p. 10)
\end{abstract}

Por muito tempo, as crianças foram marginalizadas, e os conhecimentos produzidos sobre elas advêm dos saberes produzidos pela psicologia e pela pedagogia, ou seja, pautados por um construtivismo psicológico na perspectiva das crianças dotadas de uma epistemologia em trânsito (SOARES; SARMENTO; TOMÁS, 2005). Em sentido oposto, a produção encabeçada pelas ciências sociais era restrita ao âmbito familiar e escolar, ou seja, as crianças eram vistas como filhos/as ou alunos/as, objetos de uma socialização primária e secundária.

Jenks (2002) nos desafia a reconstruirmos criticamente as diferentes posições teóricas presentes na literatura sobre a infância, para que, nesse movimento, a criança possa ser reinventada, "recuperada de forma positiva". 0 referido autor problematiza duas formas de representação da infância no pensamento social do século XIX: a primeira percebe "a criança como selvagem", fazendo uma analogia ao antropólogo "evolucionista", que tinha a posição do civilizado e sabia que o selvagem era diferente de si em termos evolutivos, sendo, 
assim, passível de estudo; e, do outro lado, nós, adultos/as tidos/ as como racionais, reconhecemos a criança como diferente, consequentemente, menos desenvolvida e a necessitar de explicação. Além dessas representações, temos ainda "a criança como natural", que se configura como a segunda forma explicitada de representação, que enfatiza que ser criança, ou simplesmente já ter tido contato ou se relacionar com estas, significa ter experiências que tornam esta categoria "normal", facilmente transformável como "natural", tal como acontecia como as categorias sexo e raça (JENKS, 2002).

Diante dessas diferentes possibilidades de representação da infância, o mesmo autor salienta que as abordagens contemporâneas dos estudos sobre crianças partem do pressuposto de que a infância não é um fenômeno natural. Em outros termos, a passagem da criança à vida adulta não é fruto diretamente do crescimento físico, muito embora este constitua uma forma de diferenciação entre as pessoas, mas que, sobremaneira, não integra uma base sólida para pensarmos o relacionamento entre criança e adulto (JENKS, 2002). Nessa linha de análise, o mesmo autor explicita que:

A infância deve ser vista como um constructo social na medida em que se refere a um estatuto social delineado por fronteiras que variam ao longo do tempo e através das sociedades, mas que são incorporadas na estrutura social e assim se manifestam através de determinados tipos de conduta que simultaneamente constroem. A infância diz então sempre respeito a um contexto cultural particular (JENKS, 2002, p.191).

Podemos conceituar a infância como categoria social do tipo geracional, e por categoria geracional compreende-se o lugar ocupado pela infância na sociedade, de acordo com o pensamento de Qvortrup (2011). 0 referido autor, no artigo intitulado "Nove teses sobre a infância como fenômeno social", discute a perspectiva de que as crianças são parte da sociedade e do mundo, sendo central relacionar infância a estruturas maiores, dilatando as condições para investigações sociológicas dessa categoria social. Cabe destacar que o campo da sociologia da infância, de certa forma, tem avivado o debate acerca das reflexões sobre a construção social da infância (SOARES; TOMÁS, 2004) e, por extensão, sinaliza o protagonismo e a participação infantil na sociedade.

Essas investigações nos oferecem a oportunidade de repensar e questionar as condições em que os conhecimentos e as 
identificações são produzidos e os lugares que as crianças ocupam nesse processo. "A sociologia da infância alargou as possibilidades teóricas de pensar a criança para além de paradigmas teóricos hegemônicos, como a psicologia, por exemplo" (ABRAMOWICZ, 2011, p.25), ou seja, a ação coletiva das crianças e os conhecimentos produzidos e reinventados cotidianamente por meninos e meninas são fundamentais para problematizarmos não mais uma infância, mas sim as múltiplas infâncias existentes.

É importante considerar que os primeiros elementos de uma sociologia da infância, tanto na perspectiva francesa como na inglesa, surgem e fixam-se por oposição à criança como mero objeto passivo de uma socialização conduzida por instituições. Neste sentido, a criança passa a ser encarada como ator social, renovando desta forma o interesse pelos processos de socialização (QUINTEIRO, 2002). Considerando a importância deste conceito para o objetivo geral desta reflexão, apresentaremos o debate em torno do conceito de socialização a partir da contribuição da sociologia da infância.

\section{Problematizações em torno do conceito de socialização}

0 conceito de socialização, historicamente, se apresenta como um processo unilateral, que por meio da condução das diversas instituições e agentes sociais objetiva a assimilação, adaptação e a integração das crianças na sociedade (MONTANDON, 2001). Para essa autora, "a crítica fundamental era que uma tal visão desse fenômeno conduz a uma abordagem enviesada das crianças, ou seja, são consideradas como objetos ou então como placas de cera sobre as quais os adultos imprimem a cultura (MONTANDON, 2001, p.52).

Tais pressupostos são oriundos do pensamento de Durkheim (1978), que foi um dos pioneiros a discutir e aprofundar sobre o conceito de socialização, dentro do campo da sociología. Para esse autor positivista, a infância era o período de passagem das crianças, por intermédio dos adultos, para a vida em sociedade. Plaisance (2010) salienta que, para Durkheim, o fim da educação é justamente a passagem de um plano individual para um plano social, e, neste caso, os familiares não são as pessoas mais indicadas para o cumprimento desse papel, exatamente pelo elo afetivo que unem todos os membros. Sendo assim, a instituição escolar passa a ser o local privilegiado para oportunizar às crianças o reconhecimento das regras sociais. "É o professor das primeiras 
séries escolares quem permitiria essa passagem para uma realidade superior, racional e impessoal, para uma moral laica e republicana" (PLAISANCE, 2010, p.225).

Nessa linha de entendimento, Durkheim compreende que a sociedade das últimas décadas do século XIX almejava construir espíritos solidários e altruístas, com o objetivo da consolidação do projeto de modernidade do próximo século (SETTON, 2005). "A educação moral das instituições família e escola teria a responsabilidade, portanto, de forjar a personalidade de um novo sujeito social, agora identificando com a proposta de uma sociedade burguesa e capitalista" (SETTON, 2005, p.338). Assim, de modo geral, a história da sociologia se constitui segundo a concepção durkheimiana de socialização, pois esses pressupostos foram recrudescidos a uma interiorização de normas e valores, como resultados de uma coerção social (PLAISANCE, 2010).

Em contraponto a esse modelo de socialização historicamente constituído como escopo teórico da sociologia, temos um conjunto de estudos que se debruçam sobre os novos entendimentos a respeito da socialização na contemporaneidade e as particularidades imbricadas nos tempos-espaços atuais (SIROTA, 2005; PLAISANCE, 2004; JAVEAU, 2005; SETTON, 2005; GRIGOROWITSCHS, 2008). Setton (2005), em seu texto "A particularidade do processo de socialização contemporâneo", discute, a partir das contribuições sociológicas de Anthony Giddens (1991), as transformações ocorridas na modernidade a partir da tríade "ressignificação do tempo/espaço, o desencaixe e a reflexividade", posicionamento que contribui para o mapeamento sobre uma nova configuração social vigente.

No que se refere à constituição das sociedades contemporâneas, Giddens (2002) ressalta a importância de se considerarem as consequências que a globalização, também pautada pelos aparatos tecnológicos, promove no rompimento das noções tidas como tradicionais e estanques de espaço/tempo, pois as mesmas estampam tanto no indivíduo quanto no coletivo "os aspectos mais pessoais de nossa existência" (GIDDENS, 2002, p.9). Em outros termos, os antigos referenciais ligados às sociabilidades, intimamente enquadradas em tempos e espaços específicos, perdem seus significados e sentidos, dando vazão a novas configurações no seio das quais se processa a vida em sociedade.

Esse sociólogo inglês, como pontua Setton (2005), identifica uma dinâmica de "deslocamento" das relações sociais de seus contextos locais de interação, o que nos sugere o reconhecimento 
de sua reestruturação por meio de extensões indefinidas de tempo-espaço. Nesse contexto, compreender e identificar os novos modos de socialização na contemporaneidade significa compreender uma nova ordem delineada nas últimas décadas, de caráter sociocultural, identificando a presença de uma maior circularidade de experiências e referências identitárias. Tais referências são evidenciadas com a entrada cada vez mais precoce das crianças nas creches e pré-escolas; as novas configurações familiares; a relevância de outras instâncias educativas, entre elas, a mídia, que, sobremaneira, ampliaram o leque de relações sociais que as crianças estabelecem, desde muito cedo. Essas novas dinâmicas relacionais implicam-nos a questionar o próprio conceito de infância, historicamente construído, principalmente, pela dependência dos adultos/ as (QVORTRUP, 2011), ou numa diferenciação cristalizada pela modernidade que autoriza os lugares ocupados pelas crianças e pelos adultos/as (PEREIRA, 2015).

É legitimo pensarmos que essas novas configurações sociais em voga nas últimas décadas não confirmam a ideia de desaparecimento da infância, apresentada por Neil Postman (2005). Trata-se de compreender que a multiplicidade de contextos e modos de vidas que as crianças compartilham, cada vez mais, reafirmam o caráter plural e multifacetado das infâncias. Pensando o processo de socialização em sua amplitude, Grigorowitschs (2008, p. 37) destaca que:

[...] os processos de socialização envolvem um ser humano individual (todo um espectro de experiências, posicionamentos, saberes, estruturas emocionais, capacidades cognitivas); suas interações, comunicações e atividades no meio social em que vive (relações familiares, escolares, interações com outras crianças, meios de comunicação de massa, religião etc.); bem como as distinções sociais que podem se manifestar em todas essas relações (sua pertença racial, de gênero, de estratificação social etc.); Essas dimensões devem ser tratadas, em seu conjunto ou em suas particularidades, segundo uma perspectiva sociológica, de acordo com um modelo "reflexivo" de socialização (Hurrelmann, 1991), que permite analisar como os indivíduos desenvolvem necessidades, capacidades, competências de agir, interesses e qualidades pessoais em tensão com as regras, expectativas e costumes sociais. Nesses processos estão em jogo aspectos multidimensionais objetivos e subjetivos, isto é, os processos de desenvolvimento da identidade e as comunicações e interações com o outro. 
Nessa direção, o sociólogo Willian Corsaro, em seus escritos, faz críticas às pesquisas que estudam crianças em uma perspectiva individualista e que consideram o processo de socialização apenas como internalização de conhecimentos e habilidades do mundo adulto. Em contrapartida, ressalta que, numa perspectiva sociológica, o processo de socialização também é um processo de apropriação, reinvenção e reprodução, que tem como mote a valorização das atividades coletivas das crianças. Desta forma, ao afirmar que o conceito de socialização traz em seu bojo uma conotação individualista e progressista inevitável, propõe o conceito de "reprodução interpretativa", onde interpretativa refere-se aos aspectos inovadores e criativos da participação infantil na sociedade, e reprodução denota a ideia de que as crianças não apenas internalizam os valores sociais, mas, além disso, contribuem significativamente para a produção e mudanças culturais (CORSARO, 2011).

\section{As crianças e seus modos de vida na contemporaneidade}

Os conceitos de infância e socialização são fundamentais para discutirmos o contexto de participação e protagonismo social das crianças. Se, no passado, palavras como vir a ser, imatura e dependente descreviam a posição da criança na sociedade, hoje, ela é considerada como sujeito de direitos e como ator social concreto. Nessa esteira, cabe indagar se essa mudança conceitual tem significado uma maior participação infantil e melhoria nas condições de vida das crianças. Para Soares e Tomás (2004), a assim denominada pós-modernidade tem se apresentado como desigual e heterogênea, e essa desigualdade tem marcado a vida de grupos sociais mais frágeis que continuam a ser excluídos das instâncias de decisão.

Confirmando essa hipótese, o relatório intitulado $A$ condição da infância no mundo em números: Cada criança conta (UNICEF, 2014) revela que temos mundialmente cerca 2,2 milhões de crianças e adolescentes, que representam $31 \%$ da população mundial. Esse estudo aponta que a nutrição infantil reduziu em $37 \%$ o atraso de crescimento das crianças; destaca-se também que a inscrição na escola primária em países menos desenvolvidos passou de $53 \%$ em 1995 para $81 \%$ em 2011. Por outro lado, temos dados alarmantes que denunciam ainda violações nos direitos das crianças, entre eles: no ano de 2012 constatou-se que 18 mil crianças morreram por causas evitáveis; as crianças mais pobres do mundo têm três vezes menos probabilidade do que as mais 
ricas de serem assistidas por um profissional qualificado no seu nascimento (UNICEF, 2014).

Outro documento lançado recentemente pela UNESCO e pela UNICEF, intitulado Reparação da promessa quebrada de Educação para Todos: resultados da Iniciativa Global Crianças Fora da Escola, mostra que a escolarização de crianças e adolescentes avançou desde 2007, porém ainda temos 121 milhões de pessoas entre 6 e 15 anos que não frequentam a escola ou evadiram; contudo, esses números se encontram na contramão da promessa da comunidade política internacional de garantir uma educação para todos até o ano de 2015. Um fato que merece destaque nesse relatório refere que o grupo mais afetado pela ausência de acesso à educação são as crianças que vivem em áreas de conflito, as que exercem algum tipo de trabalho, ou aquelas discriminadas em virtude da sua etnia, gênero ou deficiência.

Esses dados demonstram a discrepância e a desigualdade presente em diversas regiões do g'lobo no que diz respeito às possibilidades de acesso à educação formal, porém a camada mais pobre das sociedades, além das meninas e os portadores de deficiência, como demonstrado acima, são duplamente excluídos. Essa realidade compósita também endossa o que já fora apontado nesta reflexão acerca da diversidade e multiplicidade de contextos nos quais as crianças vivem. Nesse quadro, como podemos garantir formas de participação social de crianças e jovens, com a elevada diferença de oportunidades entre elas? Ou seja, notadamente, cabe destacar que a efetivação da participação discutida neste artigo se torna desafiadora exatamente para as crianças que habitam um lugar precário e desigual. Nas palavras de Perez e Passone (2010), torna-se fundamental a constituição de uma esfera pública com qualidade ético-política, que seja capaz de restituir projetos que assegurem direitos civis, políticos e sociais. Sendo assim, as políticas de atendimento à infância devem ser colocadas numa agenda que garanta às crianças seus direitos enquanto cidadãs.

\section{Nos meandros da participação infantil}

A participação infantil é um dos aspectos amplamente discutidos pelos estudos postulados pela sociologia da infância, ou seja, fazer pesquisa com as crianças tem sido uma premissa fundante para o estatuto social de meninos e meninas como sujeitos de direitos e produtores de cultura. As contribuições 
recentes dessa área têm ampliado o nosso entendimento sobre diversos aspectos das "complexas e intrincadas" relações de gênero, de classe e as relações étnicas na infância (FARIA; FINCO, 2011).

Nesse sentido, problematizar a participação infantil significa, entre outros aspectos, resgatar os direitos, interesses e necessidades das crianças, encarando-os como testemunhos do seu protagonismo e intervenção política e social (SOARES, 2006). A convenção dos direitos das crianças garante no seu artigo 12 que as crianças têm o direito de exprimir livremente a sua opinião sobre questões que lhe digam respeito e de constatar que essa opinião foi tomada em consideração, ou seja, esse princípio é fundamental para a garantia e efetivação da cidadania e participação infantil (UNICEF, 1989).

No que se refere, especificamente, ao artigo 12, Qvortrup (2010) questiona a premissa de que, somente nos assuntos com os quais mantêm relação direta, as crianças devem ter o direito de opinar livremente. Nas palavras do autor, "Essa é uma limitação grave, mas provavelmente sintomática da criança como sujeito político em nossas sociedades" (QVORTRUP, 2010, p. 780). Assim, a ideia de que estruturas maiores podem influenciar a vida das crianças de modo muito direto não está presente nas preocupações apresentadas pela Convenção. A pergunta que fica é: o campo da economia, política e do mercado, por exemplo, não diz respeito às crianças?

No Brasil, o campo da sociologia da infância tem produzido um leque de pesquisas com crianças nas quais a participação infantil é um princípio fundamental para o reconhecimento das múltiplas linguagens infantis e os diversos saberes produzidos por meninos e meninas nos ambientes coletivos da esfera pública. Essas investigações têm sido desenvolvidas a partir de intersecções com outras categorias sociais, por exemplo, gênero classe e raça/etnia. São exemplos os trabalhos produzidos por Finco $(2004,2010)$, Santiago (2014), Souza (2009), Gobbi (1997).

A efervescência dessas pesquisas se coaduna com a ideia de cosmopolitismo infantil (SOARES e TOMÁS, 2004), ou seja, um movimento de luta pelos direitos das crianças, no qual a produção acadêmica tem um papel fundamental, visto que "é precisamente no discurso acadêmico que nós conseguimos recuperar o paradigma da participação infantil (SOARES, 2002 apud SOARES; TOMÁS, 2004, p. 147). No pensamento dessas pesquisadoras, essa tentativa prática e teórica de coconstrução de uma cidadania 
da infância implica problematizarmos o conceito de cidadania, que, no passado, era restrito a um determinado grupo social, notadamente, homens, adultos e brancos. Por outro lado, na contemporaneidade, não é possível discutirmos cidadania sem nos atentarmos para as novas configurações sociais das famílias, para as mudanças provenientes das relações de gênero, para as estruturas das classes sociais, ou seja, uma ampla diversidade que implica diretamente a definição de novos papéis, espaços e sujeitos no exercício da cidadania.

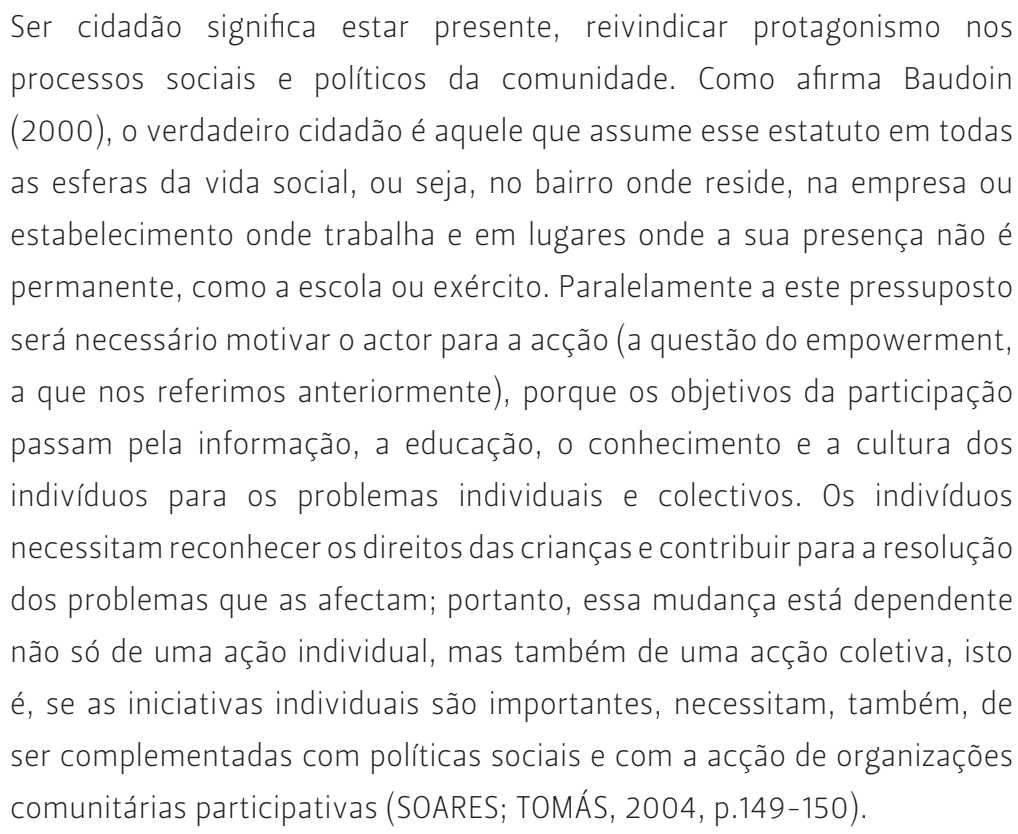

Para que se consolide a cidadania infantil é salutar promover políticas sociais e práticas que garantam visibilidade, protagonismo para as produções de meninos e meninas e, não menos importante, para suas condições de vida. 0 enfrentamento aos números alarmantes de crianças que não frequentam a escola, que morrem por causas evitáveis ou vítimas de vulnerabilidade social, em virtude de classe social, gênero ou raça, tal como apontado nos documentos de órgãos internacionais, revela-se urgente e necessário.

Sendo assim, a cidadania das crianças se efetivará na consolidação do protagonismo infantil. Nesse âmbito, Soares e Tomás (2004) apresentam três aspectos importantes nesse processo: o primeiro refere-se à organização infantil, que incentiva as relações das crianças individualmente e em grupo com o objetivo de promoção e respeito pelos seus próprios direitos, por meio de uma organização lúdica e flexível pautada pelos valores democráticos; o segundo diz respeito à participação infantil, ou seja, garantir espaços onde as opiniões e iniciativas 
tenham visibilidade e margem para negociações, garantindo assim legitimidade para o protagonismo infantil; por fim, o terceiro aspecto discute a expressão infantil, concebendo-se as manifestações de ser, sentir e pensar das crianças como pertencentes à sociedade, de acordo com seus próprios interesses, embora também na dependência das influências adultas nas interações, o que consequentemente permeará a autenticidade de tais manifestações.

Esses aspectos, que inclusive podem ser identificados no movimento das crianças quenianas em prol do direito ao brincar, são fundamentais para a promoção de uma Pedagogia da Educação Infantil que, como ponto de partida, respeite as especificidades das crianças pequenas e o direito à participação e cidadania na infância. Tais direitos, já proclamados pela Constituição Federal de 1988 e pela Lei de Diretrizes e Bases da Educação Nacional (LDB, 9494/96), que instituem a Educação Infantil como primeira etapa da Educação Básica em creches e pré-escolas, reverberaram na revisão e problematização dos conceitos de infância e também nas práticas pedagógicas desenvolvidas pelas instituições. Nesse processo, os estudos e pesquisas que têm se dedicado a pensar as infâncias e os projetos pedagógicos para esse grupo centramse na não reprodução de uma "forma escolar" (FREITAS, 2007). Para além da preparação das crianças para o ingresso no Ensino Fundamental, quais as especificidades e desafios que estão postos para a efetivação da uma Educação Infantil de qualidade que dê visibilidade e o protagonismo para as crianças pequenas?

Nessa direção, Krammer (1999), entretanto, destaca que vivemos um paradoxo, na medida em que hoje temos um conhecimento avançado sobre as infâncias, embora ainda vemos a incapacidade da nossa geração em lidar com as populações infantis e juvenis. No plano dos direitos, constatamos o mesmo panorama: apesar dos avanços verificados nos documentos internacionais sobre a situação das crianças no mundo, ainda constatamos grupos mais vulneráveis fora dessa porcentagem, inclusive o contexto ilustrado na introdução deste artigo, o das crianças quenianas.

\section{Palavras finais ou o fortalecimento da construção de uma Pedagogia da Educação Infantil}

Para impedir que a questão da participação infantil, da cidadania da infância, se transforme, mais uma vez, em acessório de consciência, de discurso, de mera auscultação e de práticas pontuais, é indispensável 
promover de uma forma consistente mecanismos teóricos e práticos, junto do grupo social das crianças e dos seus principais interlocutores (pais, professores e pares...), que permitam desvelar os intrincados trilhos da sua acção, participação e protagonismo social e político (SOARES; TOMÁS, 2004, p. 157).

0 protesto das crianças do Quênia contribuiu significativamente para instigar as problematizações, neste processo reflexivo, sobre os entraves e possibilidades da participação infantil e cidadania na infância. Evidenciamos, sobremaneira, a necessidade de continuarmos num esforço teórico, prático e institucional para a consolidação dos direitos das crianças como atores sociais concretos.

Nesse movimento, discutimos como o conceito de infância e socialização tem provocado uma representação de criança como dependente e frágil, ocultando, dessa forma, seus conhecimentos e inviabilizando as possibilidades de participação das questões que Ihe dizem respeito. Ou seja, o processo de socialização é dinâmico, vivo, pautado nas relações interpessoais que as crianças estabelecem desde a mais tenra idade, tendo em vista que, hoje, meninos e meninas passam a frequentar outros espaços educativos além do familiar desde muito cedo.

Buscamos também trazer para o centro do debate os modos de vida das crianças no mundo, por meio de dois recentes relatórios produzidos por organismos internacionais. Os dados nos mostram avanços no que concerne à escolarização de crianças e jovens, porém ainda há um caminho longo a ser percorrido, já que ainda temos 121 milhões de meninos e meninas que não frequentam a escola ou evadiram. A partir desses dados, problematizamos 0 conceito de participação e cidadania na infância como princípios fundantes para uma sociedade que respeita e coloca as crianças na pauta da agenda política e social e, nessa premissa, também pontuamos a importância do campo da sociologia da infância como produção de conhecimento sobre meninos e meninas nos espaços coletivos da esfera pública. De fato, o fortalecimento da construção do campo da Pedagogia da Educação Infantil se apresenta como possibilidade de promoção do protagonismo infantil, por meio da consolidação de práticas cotidianas emancipatórias pelas quais as crianças possam imaginar, criar, inventar e transgredir.

Nesse sentido, a construção de uma Pedagogia da Educação Infantil, que tem como foco as crianças, como sujeitos plenos de direitos e não apenas como alunos, tem colocado para este campo o desafio de conhecer as crianças para além dos modelos 
historicamente apresentados pela psicologia, propondo um diálogo com os demais campos de conhecimento, tais como a sociologia (em especial a sociologia da infância) e a antropologia, entre outros. A partir dessa perspectiva, tomar a criança a partir dela própria parecia não só interessante como necessário (CERISARA, 2004, p.40).

Dessa reflexão, derivam alguns apontamentos que nos parecem cruciais: que os interesses e a participação das crianças sejam o objetivo primeiro de políticas públicas, ações de movimentos internacionais e de práticas cotidianas que respeitem meninos e meninas como atores sociais concretos; que o brincar, direito inalienável de todas as crianças, seja garantido em todos os espaços educativos e sociais e que não esteja inteiramente à mercê de outros interesses particulares, sobretudo em benefício do capital, como os vivenciados pelas crianças quenianas; que essa demonstração de luta e coragem pelo direito ao brincar expresse, em proporções alargadas, o interesse e a possibilidade de mobilização de muitas crianças que ainda vivem em condições semelhantes, isto é, em situações de pobreza e opressão.

\title{
REFERÊNCIAS
}

ABRAMOWICZ, Anete. A pesquisa com crianças em infâncias e a sociologia da infância. In: FARIA, Ana Lúcia Goulart de; FINCO, Daniela. (org). Sociologia da Infância no Brasil. Campinas: Autores Associados, 2011.

BRASIL. Constituição da República Federativa do Brasil. Brasília, DF: Senado Federal, 1988.

BRASIL. Lei Federal nº 9394/96/LDB. Estabelece as diretrizes e bases da Educação Nacional. Diário Oficial da União. Brasília, 23 de dezembro de 1996.

\author{
CERISARA, Ana Beatriz. Em busca do ponto de vista \\ das crianças nas pesquisas educacionais: primeiras \\ aproximações. In: SARMENTO, Manuel Jacinto; CERISARA, \\ Ana Beatriz (orgs). Crianças e miúdos: Perspectivas \\ sociopedagógicas da infância e educação. Lisboa: ASA \\ editores, 2004.
}


CORSARO, William A. Sociologia da Infância. Editora Artmed, 2011.

DURKHEIM. Emile. Educação e sociologia. São Paulo: Melhoramentos, 1978.

FARIA, Ana Lúcia Goulart de; FINCO, Daniela (Orgs.). Sociologia da Infância no Brasil. Campinas: Autores Associados, 2011.

FINCO, Daniela. Faca sem ponta, galinha sem pé, homem com homem mulher com mulher: relações de gênero nas brincadeiras numa pré-escola de Campinas. Dissertação de mestrado, Faculdade de Educação-Universidade Estadual de Campinas, 2004.

Educação Infantil, espaços de confronto e convívio com as diferenças: Análise das interações entre professoras e meninas e meninos que transgridem as fronteiras do gênero. Tese de doutorado, Faculdade de Educação - Universidade de São Paulo, 2010.

GIDDENS, Anthony. Modernidade e identidade. Rio de Janeiro: Jorge Zahar Ed., 2002.

GRIGOROWITSCHS, Tamara. O conceito "socialização" caiu em desuso? - uma análise dos processos de socialização na infância com base em Georg Simmel e George H. Mead. Educação e Sociedade. Campinas, v. 29, n. 102, p. 33-54, jan./abr. 2008.

JAVEAU, Claude. Criança, infância(s), crianças: que objetivo dar a uma Ciência Social da Infância? Educação e Sociedade. Campinas, v. 26, n. 91, p. 379-389, maio/ago. 2005.

JENKS, Chris. Constituindo a criança. Educação, Sociedade e Culturas - Associação de Sociologia e Antropologia da Educação, Portugal, n. 17, 2002.

KRAMMER, Sonia. O papel social da Educação Infantil. Revista Textos do Brasil. Brasília, Ministério das Relações Exteriores, 1999.

MONTANDON, Cléopâtre. Sociologia da infância: balanço dos trabalhos em língua inglesa. Cadernos de Pesquisa. São Paulo, n. 112, p. 33-60, 2001. 
PERES, José Roberto Rus; PASSONE, Eric Ferdinando. Políticas sociais de atendimento às crianças e aos adolescentes no Brasil. Cadernos de Pesquisa, v.40, n.140, p. 649-673, maio/ ago. 2010.

PLAISANCE, Eric. Para uma sociologia da pequena infância. Educação e sociedade. Campinas: n.86, p.219-242, 2004.

QUINTEIRO, Jucirema. Infância e educação no Brasil: um campo de estudos em construção. In: FARIA, Ana Lúcia Goulart de; DEMARTINI, Zeila de Brito Fabri; PRADO, Patrícia Dias (orgs). Por uma cultura da infância. Metodologias de pesquisa com crianças. Campinas, SP: Autores Associados, 2002.

QVORTRUP, Jens. Nove teses sobre a "infância como um fenômeno social". Pro-posições, Campinas, n.64, p. 199214,2011.

QVORTRUP, Jens. Infância e política. Cadernos de Pesquisa, v.40, n.141, set./dez. 2010

PEREIRA, Rita Marisa Ribes. Crianças nas redes sociais online: novas sociabilidades e desafios para a pesquisa. II Simpósio Luso-Brasileiro em estudos das crianças. Pesquisas com crianças, desafios éticos e metodológicos. Faculdade de Educação - UFRGS. Porto Alegre, 2015.

SANTIAGO, Flávio. Meu cabelo é assim... Igualzinho o da bruxa, todo armado! Hierarquização e racialização das crianças pequenininhas negras na educação infantil. Dissertação de Mestrado. Faculdade de Educação Universidade Estadual de Campinas. Campinas, 2014.

SARMENTO, Manuel Jacinto. As culturas da infância nas encruzilhadas da segunda modernidade. In: SARMENTO, Manuel Jacinto; CERISARA, Ana Beatriz (orgs.). Crianças e miúdos: Perspectivas sociopedagógicas da infância e educação. Lisboa: ASA editores, 2004.

SETTON, Maria da Graça Jacinto. A particularidade do processo de socialização contemporâneo. Tempo Social Revista de Sociologia da USP. São Paulo, v. 17, n. 2, p. 335 350, 2005. 
SIROTA, Reginé. Emergência de uma sociologia da infância: evolução do objeto e do olhar, Cadernos de Pesquisa, São Paulo, n. 112, p. 7-31, 2001.

SOARES, Natália Fernandes. A investigação participativa no grupo social da infância. Currículo sem fronteiras, v. 6, n.1, pp.25-40, jan/jun 2006.

SOARES, Natália Fernandes; SARMENTO, Manuel Jacinto; TOMÁS, Catarina. Investigação da infância e crianças como investigadoras: metodologias participativas dos mundos sociais das crianças. Nuances: estudos sobre educação, ano XI, v. 12, n. 13, jan./dez. 2005.

SOARES, Natália Fernandes; TOMÁS, Catarina. Da emergência da participação à necessidade de consolidação da cidadania na infância... Os intrincados trilhos de acção, da participação e do protagonismo social e político das crianças. In: SARMENTO, Manuel Jacinto; CERISARA, Ana Beatriz (orgs). Crianças e miúdos: Perspectivas sociopedagógicas da infância e educação. Lisboa: ASA editores, 2004.

SOUZA, Márcia Lúcia Anacleto de. Educação e Identidade no Quilombo Brotas. Dissertação de Mestrado. Faculdade de Educação-Universidade Estadual de Campinas, 2009.

UNICEF. A condição da infância no mundo em números: cada criança conta. 2014. Disponível em: http://www.unicef.org/ spanish/sowc2014/numbers/. Acesso em: 10 jan. 2015.

A convenção dos direitos das crianças, 1989. Disponível em: https://www.unicef.pt/docs/pdf_ publicacoes/convencao_direitos_crianca2004.pdf. Acesso em: 05 jan. 2015.

UNICEF; UNESCO. Fixing the broken promise of education for all: findings from the Global Initiative on Out-of-School Children, 2015.Disponível em: http://www.uis.unesco.org/ Education/Documents/oosci-global-exsum-en.pdf. Acesso em: 20 jan. 2015.

Recebido em: 19/10/2015. Revisto em: 08/12/2015. Aceito em: 09/12/2015. 